\title{
Studies on the active SISFCL and its impact on the distance protection of the EHV transmission line
}

\author{
Chao $\mathrm{Li}^{1}$, Bin $\mathrm{Li}^{2^{*}}$, Fengrui Guo ${ }^{3}$, Jianzhao Geng ${ }^{1}$, Xiuchang Zhang ${ }^{1}$ and $\operatorname{Tim}$ Coombs $^{1}$
}

\begin{abstract}
The active saturated iron-core superconductive fault current limiter (SISFCL) is a good choice to decrease fault current. This paper introduced the principles and impedance characteristic of the active SISFCL. Then, it shows the current-limiting effects of the SISFCL. Besides, the impact of the active SISFCL on the distance protection of the EHV transmission line is evaluated. Based on that, the coordination scheme of the distance protections is proposed. A 500 kV double-circuit transmission system with SISFCLs is simulated by Electro-Magnetic Transients Program including DC (EMTDC). Simulation tests demonstrate the correctness and validity of theoretical analyses.
\end{abstract}

Keywords: Superconductive Fault current limiter (SFCL), Saturated iron core, Distance protection, Current-limiting effects

\section{Introduction}

The growth of the load and increasing demand for the stability of the power system lead to the combination of large capacity generating station and interconnection of electric power transmission and distribution systems. Consequently, the fault current is rising so greatly that the interrupting capacity of the existing electric equipment such as breakers could not withstand it [1].

One way to solve the problem is to replace the current equipment with the ones of larger capacity, which will definitely cost huge. And another method is to limit the fault current, which seems more promising. Traditional fault current limiting measures such as adopting the series reactor or the high short-circuit impendence transformer, can be equivalent to integrating an inductance or resistor with constant value to the grid. However, the method has to be at the expense of decreasing the stability of the grid and increasing the network loss. Under the circumstance, the superconductive fault current limiter (SFCL) can realize the limitation of the fault current effectively overcoming above shortcomings, because of the characteristic that it can present low impedance in the normal operation and high impedance the in the fault time. And the

\footnotetext{
* Correspondence: binli@tju.edu.cn

${ }^{2}$ Key Laboratory of Smart Grid of Ministry of Education, Tianjin University,

Tianjin 300072, China

Full list of author information is available at the end of the article
}

characteristic has broadened its application prospects in the power grid [2].

Currently the most important types of SFCL contain resistive type, bridge type, dc biased iron core type, shielded iron core type and fault current controller type [3]. And those superconductive fault current limiters can mainly be classified into two types according to different fault current limiting characteristics, that is, the resistive and inductive type. For the application in the EHV transmission line, the resistive type has to deal with several difficult problems such as high voltages at cryogenic temperatures to ensure a reliable electrical insulation, recovery time after quench to meet the requirements of the circuit breaker reclosing system. Owing to the advantages of requiring no quench of superconducting coils during operation and a smaller cryogenic system needed, the application of the dc biased saturated ironcore SFCL (SISFCL) in the EHV transmission line seems more promising. It was firstly proposed by B. P. Raju in 1980's [4]. Lots of research and experiments were carried out to develop these kinds of devices and practical prototypes were installed in distribution and transmission power grids. Among them, one type called the active SISFCL is developing very fast in China [5-7]. And a $500 \mathrm{kV}$ active SISFCL is being manufactured and schemed to integrate to the EHV transmission line in China South Grid. 
Except for the device SFCL itself, its interactions with the power grid also attract the concerns of the grid company. Therefore, it's indeed necessary to investigate the impact of the SFCL on the coordination between the SFCL and the protective relay which is able to detect fault and abnormal operation conditions with high sensitivity and reliability $[8,9]$. However, the topic of the coordination between the active SISFCL and the protection was not discussed directly with depth studies. And we will discuss the topic in the following. Besides, we introduce the working principle of the saturated iron core superconductive fault current limiter and its current-limiting effects in the electric power transmission line. There is no doubt that the application of superconducting fault current limiters in the power grid will be promising if their negative impacts on the operation of the power grid could be significantly reduced.

\section{Working principle and current limiting effects of an active SISFCL}

Working principle and impedance characteristic of the active SISFCL

As shown in Fig. 1, the active SICSFCL is composed of two iron cores, ac coils, and a superconductor dc circuit with high-speed switch control. The ac coils wounded around the iron cores are integrated to the power grid and the inductance of the ac coils displays the impedance characteristic of the active SISFCL, which is low impedance during normal power transmission and high impedance for fault current limiting. The dc magnetization circuit with high-speed switch control has the following functions: driving the two iron cores into deep saturation during normal condition, stopping the dc current supply at once a fault current occurs and providing the dc magnetizing again current as soon as the fault is cleared. It is
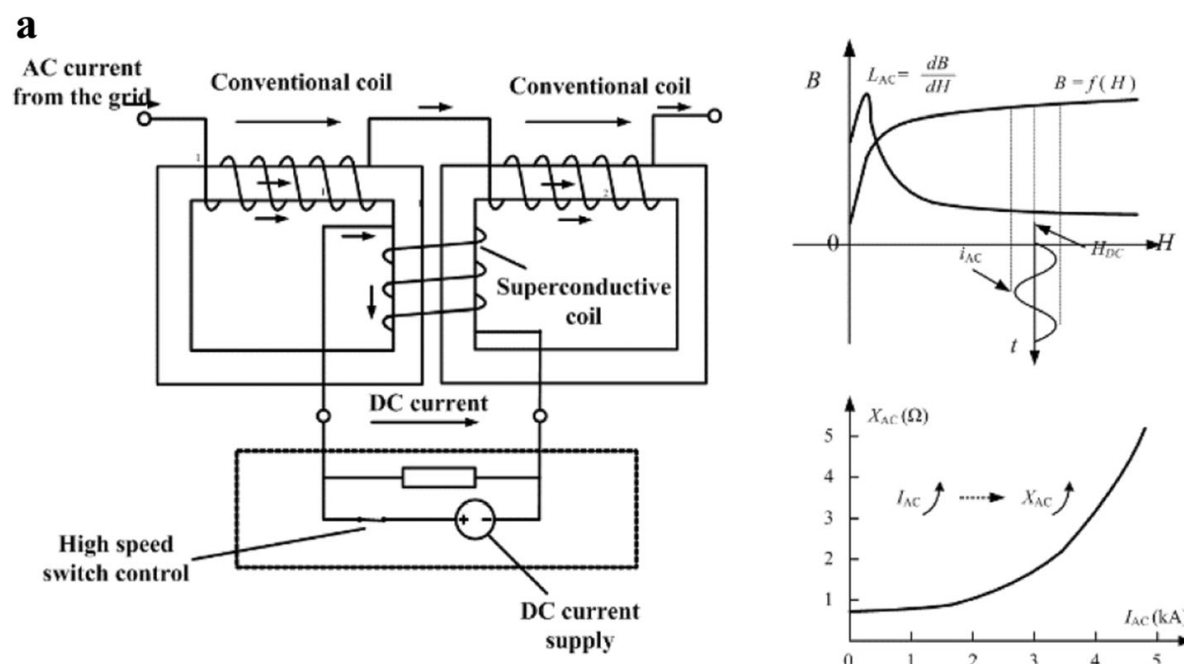

b
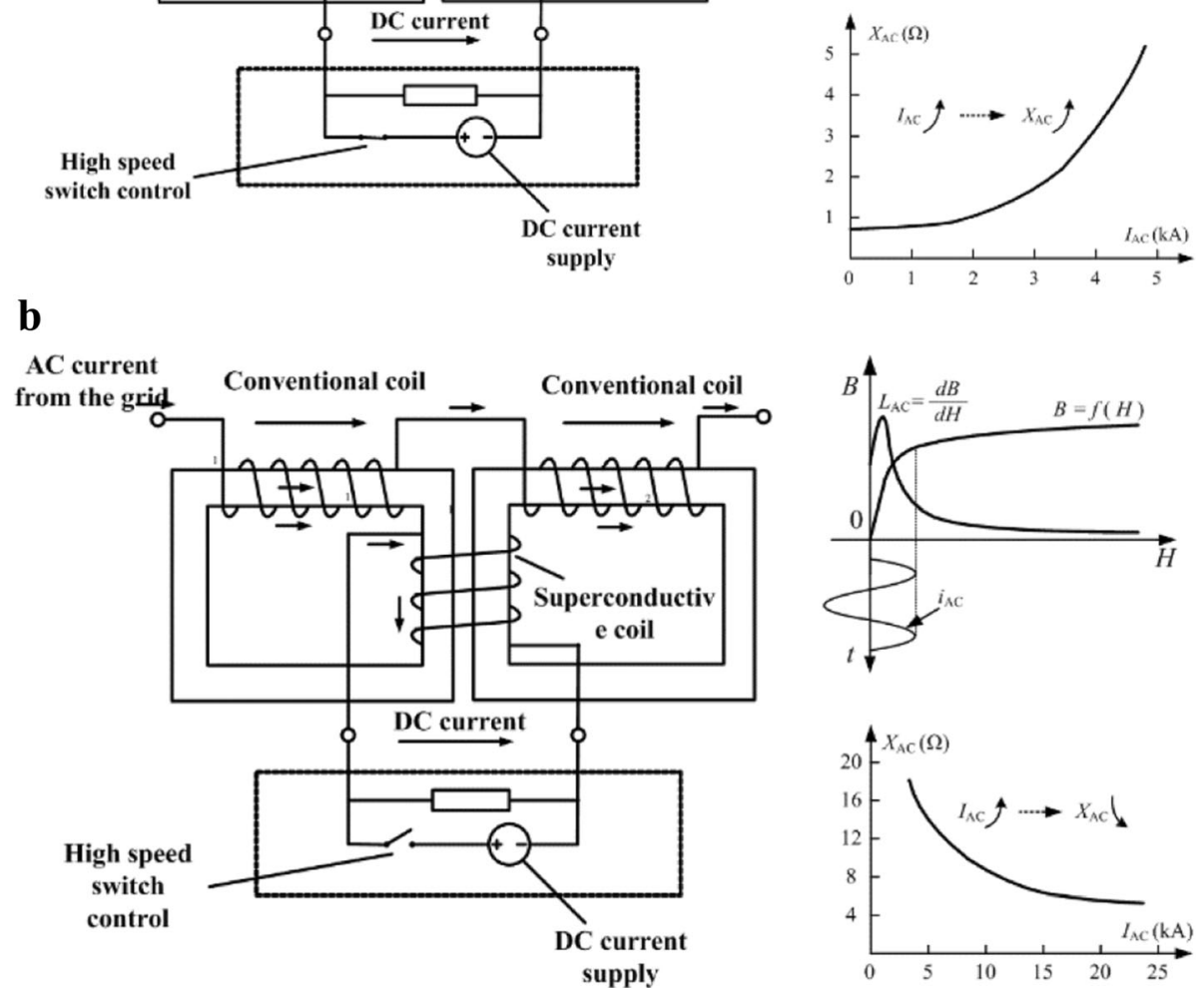

Fig. 1 Structure diagram of the active SISFCL and operational states of the active SISFCL. a Steady state and impedance characteristic; $\mathbf{b}$ Current-limiting state and current-limiting impedance characteristic 
Table 1 Current of the three-phase fault and single-phase fault

\begin{tabular}{|c|c|c|c|c|c|}
\hline & \multicolumn{2}{|c|}{$\begin{array}{l}\text { Current of three-phase } \\
\text { fault(kA) }\end{array}$} & \multicolumn{2}{|c|}{$\begin{array}{l}\text { Current of single-phase } \\
\text { fault(kA) }\end{array}$} & \multirow{2}{*}{$\begin{array}{l}\text { Numbers of } \\
\text { substation } \\
\text { exceeding 63kA }\end{array}$} \\
\hline & Max & Average & Max & Average & \\
\hline 2010 & 62 & 45.7 & 61.8 & 41.6 & 0 \\
\hline 2015 & 70.9 & 47.9 & 72.9 & 43 & 13 \\
\hline 2020 & 78.7 & 52.7 & 72.5 & 48 & 17 \\
\hline
\end{tabular}

$63 \mathrm{kA}$ is the interrupting capacity of the breakers in the $500 \mathrm{kV}$ substation

the superconductor dc circuit with high-speed switch control that help the active SISFCL overcome the disadvantages of the conventional SISFCL such as high cost, large size and induced overvoltage in the dc circuit. Consequently, two operational states of the active SISFCL are invited: the steady sate when the high speed switch is on and the current-limiting state when the high speed switch is off.

The two operational states with different impedance characteristics are depicted in Fig. 1a and b.

(1) Steady state: during the normal operation condition, both of the two iron cores are driven into saturation at points $\mathrm{H}_{\mathrm{DC}}$ by the dc biased current in the $\mathrm{dc}$ superconductive magnetization circuit. The normal current in the ac coils is low enough to keep the cores fully saturated. Thus, the magnetic permeability is so small that the active SISFCL shows low impedance, as shown in Fig. 1a. Besides, the impedance of the active SISFCL is nonlinear positive correlation with the current flowing through the active SISFCL.

(2) Current-limiting State: the high-speed switch turned off dc current supply at the onset of the current limiting stage, decoupling the dc coils and ac coils in less than ten milliseconds. The de-saturating iron cores came to the points where the magnetic permeability of the iron core is large enough to make the SISFCL show a high impedance value, as shown in Fig. 1b. In addition, the impedance of the active SISFCL decreases with the increase of the fault current.

As for the previous $35 \mathrm{kV}$ and $220 \mathrm{kV}$ active SISFCLs, the six iron-core frames of the three phases are conjugated in a hexagonal structure, sharing only one dc superconductor bias coil. Different from the previous three-phase-in-one structure of the $35 \mathrm{kV}$ and the $220 \mathrm{kV}$ SISFCLs, the $500 \mathrm{kV}$ device is comprised of three independent single-phase SISFCLs, which makes it possible that the DC circuits of each single-phase SISFCL operate on its own.

Due to nonlinear characteristic of the fundamental magnetization curve, the impedance of the active SISFCL is not constant but relates to the current flowing through the SISFCL and its operation state.

\section{Current-limiting effect of the active SISFCL}

With the interconnection of the $500 \mathrm{kV}$ power grid, the Guangdong Province Grid in China is achieving full closed loop operation in 2015. Hence, the fault current in 2010 and the fault current forecasted to be in 2015 and 2020 in shown in Table 1 [10].

Electromagnetic Transient Programming including DC (EMTDC) software has been used to investigate the current-limiting effects of the active SISFCL. The simulation model has been built according to the real data from $500 \mathrm{kV}$ transmission system in China, as shown in Fig. 2.

Assuming a single-phase fault and a three-phase fault occurred in the outlet of the substation m respectively, the fault current of the transmission line with and without the active SISFCL is shown in Fig. 3. For the single phase fault, the RMS value of the fault current is as large as $49 \mathrm{kA}$ without installing the active SISFCL in the substation. However, the RMS value of the fault current decreased to $17 \mathrm{kA}$ in the presence of the active SISFCL. Similarly, the current of the three-phase fault can go down to $32.45 \%$ with the active SISFCL.

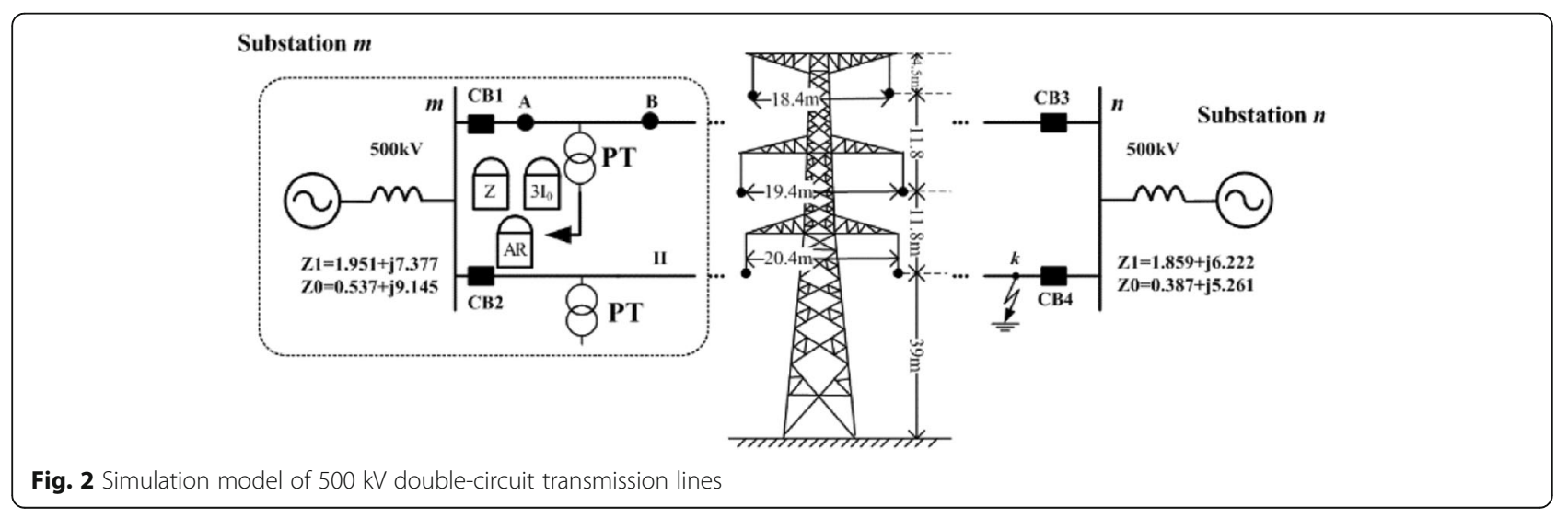




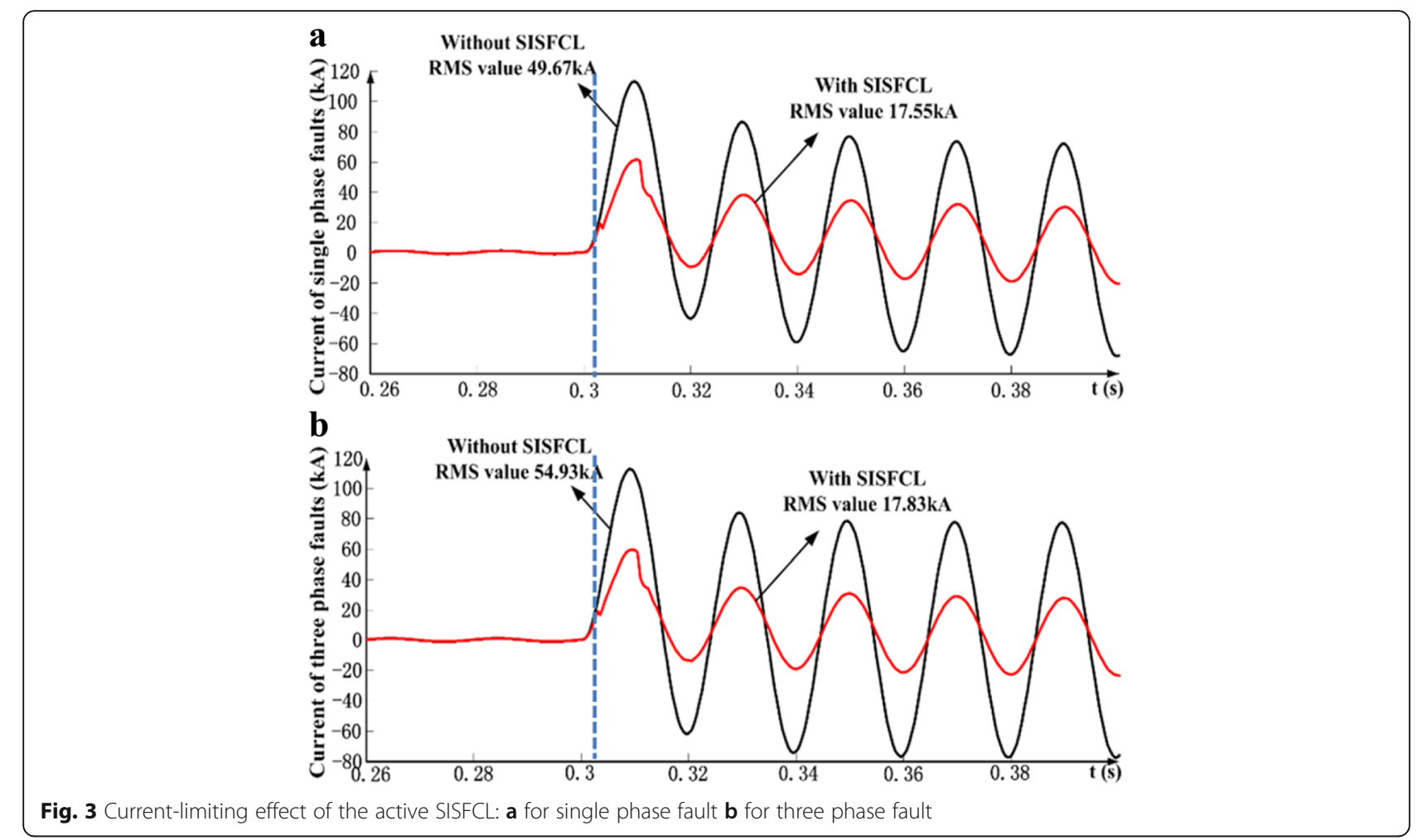

\section{Coordination of the active SISFCL and the distance protection}

Impact of the active SISFCL on the distance protection for the EHV transmission line

The objective is to determine how the location of the SISIFCL impacts the distance protection, which is a type of protection widely applied in the EHV transmission line.

For the convenience of daily maintenance and repairs, it's a good option to install the SISFCL in the transformer substation (see Fig. 2). Hence we have two choices to locate the PTs for distance protection, namely point $A$ and point $B$. If the SISFCL is installed at side A, it means the distance protection of the local side will not contain the SISFCL and the distance protection of the location will not be influenced by the SISFCL but the remote side will be. If installed at side $B$, the SISFCL will be included by the distance protection of local side and its impact on the distance protection of local and remote side should be analyzed in detail.

Distance relays are usually used to protect high voltage transmission lines. They can respond to the impedance of the distance from the fault location to where the relay is installed. In order to avoid maloperation and misoperation of the distance relays, the three-zone distance protection is adopted.

It's a fundamental principle of distance relay that the voltage and current used to energize the appropriate relay are such that the relay will measure the positive sequence impedance to the fault.
Principles for coordination of the active SISFCL and the distance protection

In order to ensure the sensitivity for the fault occurring at the end of the transmission line, we must be definite about the impedance of the SISFCL. However, the impedance of the active SISFCL has two characteristics: a) the impedance is variable. b) the impedance is a nonlinear function of the current flowing through the SISFCL. Therefore, the two impedance characteristics make the impact of the active SISFCL on the distance protection coordination more complex than that of other SFCLs.

According to above analysis, the impedance of the SISFCL is a function of the current and the current determine whether the active SISFCL stays in steady state or current-limiting state. Besides, there is great difference in value of the current under the circumstance of different fault points, different fault types, different system operation modes and so on.

According to the principle of the distance protection, the second zone of the distance protection should contain the impedance of the whole protected line and the largest impedance of the active SISFCL and its sensitivity for the fault shall be guaranteed. But whether the second

Table 2 The impedance of different fault points on transmission line MN

\begin{tabular}{llllll}
\hline Fault position (\%) & 15 & 45 & 60 & 75 & end \\
Impedance $(\Omega)$ & 8.85 & 9.2 & 9.6 & 9.9 & 10.8 \\
\hline
\end{tabular}




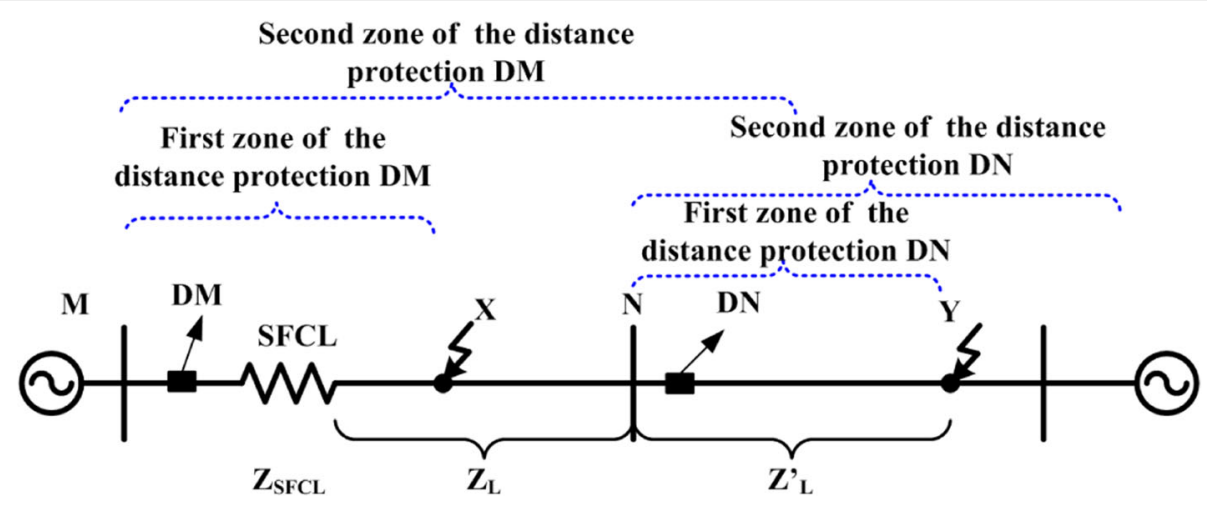

Fig. 4 Configuration of the distance protection

zone will overreach the first zone of the next distance protection shall also be verified. The conventional scheme for verifying overreach is suitable for the distance relay, which includes the active SISFCL, owing to the special impedance characteristics which is introduced above. In the following, a new scheme for verifying overreach will be discussed in detail.

On the base of Fig. 1, the impedance of the active SISFCL is negative correlation with the current flowing through. That's to say, the smaller the current is, the larger the impedance of the SISFCL will be. Hence, for all the faults $\mathrm{X}$ happened on the transmission line $\mathrm{MN}$, the largest impedance of the active SISFCL will appear when the fault occurred at the Point N. The simulation by PSCAD/EMTDC verified above analysis, as shown in Table 2 .

In Fig. 4, the largest impedance of the SISFCL $\left(Z_{S F C L . \max }\right)$ appears when a phase-to-phase fault happens at the end of the transmission line under the circumstance of the system minimum operating mode. The second zone of the distance protection DM should be expressed as:

$$
Z_{I I . \mathrm{DM}}=K_{\operatorname{sen}}\left(Z_{L}+Z_{\text {SFCL.N. } \max }\right)
$$

When a fault happens at point $\mathrm{Y}$ of the next neighbor transmission line, the smallest impedance of the active SISFCL should be used to verify whether the distance protection DM will overreach. And the its smallest impedance appears in the situation of the largest fault current, namely the current of a three-phase fault in the system maximum operating mode. Hence the measure impedance of the local distance relay can be expressed:

$$
Z_{\mathrm{m}}=Z_{L}+Z_{S F C L . Y \cdot \min }+Z_{L}^{\prime}
$$

If $Z_{\mathrm{m}}>Z_{I I}$, it means there is no overreaching for DM. If $Z_{\mathrm{m}}<Z_{I I}$, it means there is overreaching for DM.

Hence, the current flowing through the active SISFCL during the fault at point $\mathrm{Y}$ is smaller than that when the fault happens in the $Z_{L}$. Consequently, the impedance of the active of SISFCL will become larger and help to avoid the overreach of the distance protection of DM. The characteristic of the SISFCL is very helpful for the coordination of the distance protection for a long transmission line with a much shorter neighbor transmission line.

\section{Conclusions}

This paper demonstrates the active SISFCL is a good solution to the problem of increasing fault current, using the real data from South China Grid. The results have shown that the application prospects of the active SISFCL is promising. According to its operational principle in the current-limiting state, the impedance of the active SISFCL decreases with the increase of the fault current nonlinearly. This characteristic can help to avoid the overreach of the distance protection. Besides, a setting scheme for the distance protection in the EHV transmission has been proposed.

Authors' contributions

Manuscript is approved by all authors for publication.

Competing interests

The authors declare that they have no competing interests.

\section{Author details}

${ }^{1}$ EPEC Superconductivity Group, University of Cambridge, Cambridge CB3 OFA, UK. ${ }^{2}$ Key Laboratory of Smart Grid of Ministry of Education, Tianjin University, Tianjin 300072, China. ${ }^{3}$ State Grid Tianjin Electric Power Company, Tianjin 300010, China.

Received: 14 July 2016 Accepted: 16 November 2016

Published online: 07 December 2016

References

1. Zhang, Y., \& Dougal, R. A. (2012). State of the art of Fault Current Limiters and their applications in smart grid. San Diego: IEEE General Meeting of Power and Energy Society.

2. Ye, L., Lin, L. Z., \& Juengst, K.-P. (2002). Application studies of superconducting fault current limiters in electric power systems. IEEE Transactions on Applied Superconductivity, 12(1), 900-903.

3. Noe, M., \& Steurer, M. (2007). High-temperature fault current limiters: concepts, applications and development status. Superconductor Science and Technology, 20(3), 15-27. 
4. Raju, B. P., Parton, K. C., \& Bartram, T. C. (1982). A current limiting device using superconducting d.c. bias applications and prospects. IEEE Transactions on Power Apparatus and Systems, 101, 3173-3177.

5. Xin, Y., Gong, W. Z., \& Cao, Z. J. (2007). Development of saturated iron core HTS fault current limiters. IEEE Transactions on Applied Superconductivity, 17(2), 1760-1763.

6. Hong, H., Cao, Z., Zhang, J., et al. (2009). DC magnetization system for $35 \mathrm{kV} / 90 \mathrm{MVA}$ super-conducting saturated iron-core fault current limiter. IEEE Transactions on Applied Superconductivity, 19(3), 1851-1854.

7. Xin, Y., Gong, W. Z., Niu, X. Y., et al. (2009). Manufacturing and test of a 35 kV/90 MVA saturated iron-core type superconductive fault current limiter for live-grid operation. IEEE Transactions on Applied Superconductivity, 19(3), 1934-1937.

8. Li, B., Li, C., \& Guo, F. (2014). Overcurrent Protection Coordination in a Power Distribution Network With the Active Superconductive Fault Current Limiter. IEEE Transactions on Applied Superconductivity, 24(5), 5602004.

9. Jin-Seok, K., Sung-Hun, L., \& Jae-chul, K. (2012). Study on application method of superconducting fault current limiter for protection coordination of protective devices in a power distribution system". IEEE Transactions on Applied Superconductivity, 22(3), 5601504.

10. Wei, L., et al. (2013). Prospects for application of superconducting fault current limiter in Chinese power system (Proceedings of 2013 IEEE International Conference on Applied Superconductivity and Electromagnetic Devices Beijing, China, pp. 513-516).

\section{Submit your manuscript to a SpringerOpen ${ }^{\circ}$ journal and benefit from:}

- Convenient online submission

- Rigorous peer review

- Immediate publication on acceptance

- Open access: articles freely available online

- High visibility within the field

- Retaining the copyright to your article

Submit your next manuscript at $\gg$ springeropen.com 